3 Хмелева К. Э. Анализ факторов, влияющих на формирование банковской конкуренции в Российской Федерации // Экономические науки 2014, 3(112), С. 77-80

${ }^{4}$ Влезкова В. И. Влияние глобализации на банковские структуры: Трансформационные процессы // Вопросы экономики и права, 2012, № 6, С. 157-161

5 Вишневер В.Я. Взаимосвязь глобализации и монополизации мировой экономики //Экономические науки, 2003, №5. С. 55-60.

\title{
THE IMPACT OF GLOBALIZATION ON BANKING COMPETITION IN RUSSIA
}

\author{
(C) 2019 Bolshakova Regina Yurievna \\ Student \\ (C) 2019 Vishnever Vadim Yakovlevich \\ Candidate of Economics, Associate Professor \\ Samara State University of Economics \\ E-mail: ab3535@mail.ru
}

\begin{abstract}
Keywords: globalization, competition, bank competition, banking market, liberalization of the markets.

The article considers the patterns of globalization of the world economy, revealed the impact of globalization on banking competition in Russia.
\end{abstract}

УДК 338

Код РИНЦ 06.00.00

\section{ЭКОНОМИЧЕСКАЯ ПРИРОДА ВАЛЮТНОГО РИСКА В КОММЕРЧЕСКИХ БАНКАХ}

\author{
(c) 2019 Борисова Александра Евгеньевна \\ магистрант \\ (C) 2019 Жегалова Елена Валерьевна \\ кандидат экономических наук, доцент \\ (c) 2019 Кузнецова Алина Олеговна \\ магистрант \\ Самарский государственный экономический университет \\ E-mail: crashedinatunebox@gmail.com
}

Ключевые слова: коммерческие банки, риски, валютные риски, операционный валютный риск, трансляционный валютный риск экономический валютный риск.

В статье представлено определение валютного риска в коммерческом банке. Рассматривается экономическая природа валютного риска. Приводятся основные методы управления валютным риском в коммерческих банках. 
Современная экономика подвержена процессам глобализации. В данных условиях различные предприятия, организации, банки и другие хозяйствующие субъекты все чаще в процессе своей деятельности взаимодействуют с мировым рынком. Также сталкиваются с проблемами, которые характерны только для международного взаимодействия и не присущи деятельности, осуществляемой только внутри рынка определенной страны.

Коммерческие банки по роду своей деятельности все больше и чаще работают с различными внешними структурами такими как другие иностранные банки, зарубежные организации и так далее. При этом коммерческие банки осуществляют операции покупки, а также продажи иностранной валюты, конверсионные сделки, международные расчеты, определяя курсы иностранных валют и др.

В современном мире, при совершении валютных операций, коммерческие банки, а также клиенты этих банков постоянно бывают подвержены валютному риску. В связи с данной особенностью деятельности коммерческих банков тема валютного риска и управления им является актуальной в современных условиях развития как мировой экономики в целом, так и национальных экономик отдельных стран.

В общем смысле под валютным риском понимают существующую возможность потери денежных средств, выраженных в национальной валюте, при покупке или же продаже иностранной валюты по различным курсам.

Стоит отметить, что в коммерческих банках валютный риск наступает, когда совершаются как торговые, так и и неторговые операции. К сожаленю, нет возможности точно определить величину будущего обменного курса, который будет в следующем периоде, независимо от существующих оценок и прогнозов. Именно такое неопределенное движение и создает угрозу для доходов коммерческих банков, если данное движение находится в нежелательном направлении.

В коммерческом банке валютный риск возникает при осуществлении им международной деятельности. К данному виду деятельности относится:

- совершение валютных операций;

- совершение зарубежного кредитования;

- осуществление инвестиционной деятельности коммерческим банком;

-совершение международных платежей, а также и расчетов;

- финансирование внешней торговли, международны гарантийных операций

- страхование валютных и кредитных рисков и др.

В условиях глобализации национальные экономики различных стран рост международного бизнеса также приводит и к увеличению подверженности валютному риску для многих компаний.

В современной экономической литературе обычно принято выделять несколько видов валютного риска, представленных ниже.

К основным видам валютного риска относится операционный валютный риск. Данный вид риска представляет собой вероятность получения денежных потерь по конкретным операциям, выраженным в иностранной валюте. Непосредственно риск состоит в том, что существует возможность изменения величины поступлений или платежей при пересчете в национальной валюте. Описываемый вид риска возниает при заключении торговых контрактов, а также при получении или же предоставлении кредитов, выраженных в иностранной валюте. 
Воздействие такого операционного риска относится к подверженности, которая может быть вызвана фрактической транзакцией. Данная операция происходит в бизнесе при участии иностранной валюты.

В бизнесе все денежные операции осуществляются для получения прибыли как конечного результата. Стоит отметить, что не всегда такой результат оказывается положительным для банка. ${ }^{1}$

Также, важно отметить следующий момент, что уровень операционного риска, зависит от следующих позиций:

- адекватность инфрормационных систем;

- средства контроля;

- качество операционных процедур и другие.

В научной литературе выделяют трансляционный валютный риск. Данный вид риска связан с осуществлением бухгалтерского учета. Он возникает при изменении балансовой стоимости активов и обязательств коммерческого банка, доходов и расходов, прибыли (убытков) компании, возникающих в результате обмена (конвертации) или перевода финнансовой отчетности расположенного в другой стране дочернего предприятия.

Напрямую трансляционный риск не влияет на денежные потоки коммерческого банка, но важно отметить, что он опасен для компаний из-за его потенциального влияния на сообщаемые консолидированные, то есть объединенны, доходы.

Также стоит отметить, экономический валютный риск. Данный вид риска состоит в следующем. Стоимость активов и пассивов коммерческого банка может меняться в большую или же меньшую сторону (в национальной валюте) по причине будущих изменений валютного курса.

Экономическому риску в наименьшей степени подвержены такие компании, которые несут издержки исключительно в национальной валюте. Также такие компании не имеют альтернативных источников факторов производства, на котором могли бы отразиться изменения валютного курса. Эти компании, реализующие продукцию только на внутреннем рынке страны, не встречают конкуренции со стороны товаров, цены на которые могут стать более выигрышными из-за положительного для банка изменения курса. Но также стоит отметить, что даже такие компании не полностью защищены, по причине того, что изменения обменного курса могут иметь последствия, которых не сможет избежать ни одна из присутствующих на рынке фирм.

Экономическое воздействие данного вида риска является достаточно долгосрочным эффектом воздействия транзакции. Если организация постоянно подвергается неизбежному воздействию иностранной валюты на долгосрочную перспективу, то, следовательно, она имеет экономический эффект. Такое воздействие на валюту приводит к влиянию на рыночную стоимость компании поскольку риск характерен для деятельности компаний и на протяжении многих лет оказывает значительное влияние на величину получаемой ими прибыли.

Все выше описанные виды валютных рисков крайне важны и необходимы для лучшего понимания механизма функционирования международного финансового менеджмента. Анализ воздействия и поведения иностранной валюты помогает не только правильно взглянуть на бизнес фирмы, но и принимать обоснованные решения. 
В связи с тем, что влияние валютного риска, оказываемое на деятельность коммерческих банков, велико и имеет сильные последствия для их дальнейшего функционирования и существования в целом, необходимо принимать меры для того, чтобы иметь возможность управлять риском.

Валютный риск можно уменьшить путем применения коммерческими банками в своей деятельности различных методов, среди которых существуют защитные и валютные оговорки, лимитирование, хеджирование и др. Рассмотрим их более подробно.

Защитные оговорки представляют собой договорные условия, включаемые по соглашению сторон в частные и межгосударственные соглашения, которые предусматривают возможность изменения (или другими словами пересмотра) первоначальных условий договора в процессе его исполнения.

В соответствии с валютной оговоркой сумма денежных обязательств может меняется в зависимости от изменения курсового соотношения между валютой платежа и какой-либо другой валютой или же группой валют, более устойчивой, а также определенной в качестве валюты оговорки.

Валютой оговорки может быть валюта сделки либо третья валюта. В условиях плавающих валютных курсов в качестве валюты оговорки используют различные комбинации из нескольких валют (так называемые валютные корзины). Данный вид валютной оговорку именуется мультивалютной.

В качестве метода управления валютным риском также применяют лимитирование. Под лимитированием понимают установление количественных ограничений на сумму и вид валют, курс которых наиболее подвержен резким волатильным изменениям.

Стоит отметить, что многие международные компании управляют валютным курсом путем хеджирования его с использованием сложных финансовых инструментов.

В общем смысле под хеджированием понимают страхование сделки на рынке реального товара от риска неблагоприятного изменения цены с помощью совершения контрсделки (заключения компенсирующей противоположной сделки) на рынке срочных контрактов. Для хеджирования используются производные финансовые инструменты такие как фьючерсы и опционы.

Под валютным хеджированием в научной литературе понимают заключение срочных сделок на покупку или же продажу иностранной валюты в целях уменьшения риска потерь от неблагоприятного изменения курсов валют. ${ }^{2}$

Валютное хеджирование осуществляется путем заключения сделки со срочным валютным контрактом и одновременно с противоположной сделкой на наличную валюту с тем же сроком поставки.

Хеджирование предполагает снижение неопределенности, связанной с денежными потоками в результате положительного валютного воздействия. Покупка или продажа валюты по предопределенной будущей дате и цене является одним из способов хеджирования валютного риска.

Для уменьшения валютного риска можно использовать следующие основные приемы хеджирования в различных ситуациях:

1. В ситуации, когда ожидается падение курса национальной валюты:

- осуществить продажу национальной валюты, выбрав вторую валюту для совершаемой сделки; 
- необходимо сократить объем операций, производящихся с ценными бумагами в национальной валюте, а также сократить объем наличности;

- ускорить получение дебиторской задолженности, выраженной в национальной валюте;

- отложить получение, начать накопление дебиторской задолженности, выраженной в иностранной валюте;

- отложить платеж по кредиторской задолженности в национальной валюте;

- увеличить заимствование (передачу) в национальной валюте;

- ускорить и увеличить импорт продуктов за твердую валюту;

- ускорить выплату вознаграждений, заработной платы, дивидендов и так далее иностранным акционерам, партнерам и кредиторам;

- направлять счета импортерам в национальной валюте, а экспортерам в иностранной валюте.

2. В ситуации, когда ожидается рост курса национальной валюты необходимо произвести действия, обратные изложенным для 1-й ситуации, а именно:

- осуществить покупку национальной валюты;

- необходимо увеличить объем операций, производящихся с ценными бумагами в национальной валюте, а также увеличить объем наличности;

- уменьшить заимствование (передачу) в национальной валюте и т.д.

Таким образом, в заключении необходимо отметить, что на современном этапе развития экономик необходимое взаимодействие разнообразных структур (предприятий, организаций, банков и др.) сопровождается различными видами рисков. Мировая экономика в целом, а также и национальные экономики отдельных государств подвергаются влиянию валютного риска

Также не представляется возможным избежание негативного воздействия, оказываемого валютным риском, на коммерческие банки.

Коммерческие банки подвержены валютному риску, исходящему из осуществления его деятельности на международном рынке. Невозможно определить величину будущего обменного курса в следующем периоде вне зависимости от существующих оценок и прогнозов. Именно такая неопределенность создает угрозу для доходов коммерческих банков, если изменение курса находится в нежелательном для банка направлении.

Все вышеуказанные в статье факторы и определяют необходимость управления валютным риском и его совершенствования для обеспечения финансовой устойчивости всех участников международного рынка, и прежде всего коммерческих банков. $390 \mathrm{C}$.

${ }^{1}$ Круи М., Галай Д., Марк Р. Основы риск-менеджмента. Учебное пособие; Юрайт - М., 2014. -

2 Словарь финансово-экономических терминов /А. В. Шаркова, А. А. Килячков, Е. В. Маркина и др.; под общ. ред. д. э. н., проф. М. А. Эскиндарова. - М.: Издательско\&торговая корпорация "Дашков и К", 2015. -1168 с..

${ }^{3}$ Амосова Н.А. Система риск-менеджмента в коммерческом банке / Н.А. Амосова. - Иваново, 2014. - $200 \mathrm{C}$.

${ }_{4}^{4}$ Волков, А. А. Управление рисками в коммерческом банке: Практическое руководство / А. А. Волков. - М.: Омега-Л, 2015. - 156 с. 


\title{
THE ECONOMIC ESSENCE OF CURRENCY RISK OF A COMMERCIAL BANK
}

\author{
C 2019 Borisova Alexandraa Evgenevna \\ Student \\ (c) 2019 Zhegalova Elena Valerevna \\ Candidate of Economics, Associate Professor \\ (c) 2019 Kuznetcova Alina Olegovna \\ Student \\ Samara State University of Economics \\ E-mail: crashedinatunebox@gmail.com
}

Keywords: commercial banks, risks, exchange rate risks, operational currency risk, translational currency risk, economic currency risk.

The paper presents the definition of foreign exchange risk in commercial banks. Basic methods for currency risk management in commercial banks are suggested.

УДК 311.312

Код РИНЦ 83.00 .00

\section{СТАТИСТИЧЕСКИЙ АНАЛИЗ СТРУКТУРЫ МАЛОИМУЩЕГО НАСЕЛЕНИЯ В РОССИЙСКОЙ ФЕДЕРАЦИИ}

\author{
() 2019 Букина Анастасия Александровна \\ магистрант \\ (c) 2019 Чистик Ольга Филипповна \\ доктор экономических наук, профессор \\ Самарский государственный экономический университет \\ E-mail: nastnk97@yandex.ru, yurijchistik@yandex.ru
}

Ключевые слова: бедность, малоимущие домашние хозяйства, прожиточный минимум, выборочные обследования, финансовое и материальное положение.

Была проанализирована категориальная структура и дана оценка финансового и материального положения малоимущего населения России.

Бедность является острой общественной проблемой. Бедность влияет на здоровье, уровень образования и культуры наших граждан, она ведет к понижению уровня и качества жизни, росту преступности.

Бедность следует рассматривать как состояние отсутствия необходимых ресурсов для обеспечения удовлетворительного образа жизни ${ }^{1}$. Бедность исследовалась рядом авторов 2,3,4. 